\title{
Assessment of the Lake Trout Fishery in Lake Superior: 1929-1950
}

\author{
A. L. JENSEN \\ School of Natural Resources, University of Michigan \\ Ann Arbor, Michigan 48109
}

\begin{abstract}
The logistic surplus production model is applied to the lake trout (Salvelinus namaycush) fishery of district MS-4 in Lake Superior from 1929 to 1950. Comparison of the equilibrium stock production curve with observed yield and effort data indicates that the fishery became overexploited at about the same time that the sea lamprey first was observed in the lake. This was a period during which fishermen were moving to Lake Superior from the other lakes as lake trout stocks were collapsing as a result of sea lamprey predation. The sharp decline in lake trout yields from Lake Superior occurred about 10 yr later. Collapse of the lake trout stocks apparently was caused by sea lamprey predation on a population that was stressed by intensive exploitation.
\end{abstract}

Dramatic changes in the composition and relative abundance of the fish species of the upper Great Lakes are well documented by commercial catch statistics (Baldwin and Saalfeld 1962; Jensen and Buettner 1976). These changes in the Great Lakes fisheries have been the subject of extensive research efforts which were summarized in the 1971 symposium on salmonid communities in oligotrophic lakes (J. Fish. Res. Board Can. 29[6]:611-986, 1972). The causes of change in the Great Lakes fisheries are complex, but most authorities agree that the major factors are intensive fishing, introduced species, invading species, and environmental change. The effects of fishing on the Great Lakes fish stocks should be the easiest factor to quantify because both catch and effort data for commercial fishing are available for many years.

The lake trout (Salvelinus namaycush) is a fish of importance on the upper Great Lakes and collapse of the lake trout stocks in the 1950's was devastating to both the recreational and commerical fishing industries. The commerical lake trout fishery in Lake Superior was stable, producing between 1.36 and 2.04 million $\mathrm{kg}$ annually, from 1929 to 1953. After 1953, yield began a steep decline. A combined program of sea lamprey control, stocking, and prohibition of commercial fishing have resulted in partial recovery of the lake trout stocks; the trout are now abundant but there is little natural reproduction.

The changes that occurred in the lake trout stocks of Lake Superior have been reported in detail by Hile et al. (1951) and Pycha and King (1975). Hile et al. (1951) believed that increasing fishing effort and a declining abundance index were related but they could not quantitatively relate abundance and fishing effort. Pycha and King (1975) reviewed more recent data as well as the data reported by Hile et al. (1951) and concluded that intensive fishing in the early 1950's and severe sea lamprey predation in the late 1950's caused the collapse of the lake trout fisheries in the mid-1950's. Sakagawa and Pycha (1971) applied Ricker's (1975) dynamic pool model to the lake trout of south central Lake Superior using age and growth data collected in 1948. They concluded that the pre-lamprey lake trout population was in a steady state before 1950, but that it was being overexploited. Sakagawa and Pycha (1971) estimated the instantaneous fishing mortality coefficient as 0.50 ; the value that would have produced the maximum yield per recruit was between 0.20 and 0.30 .

In this study another standard fishery assessment technique, the surplus production model, is applied for assessment of the lake trout fishery in Lake Superior from 1929 to 1950. The objectives of this assessment are to determine the level of lake trout exploitation before sea lamprey predation became important and to demonstrate the utility of standard fishery models as tools for management of the Great Lakes fisheries. The surplus production model appears particu- 


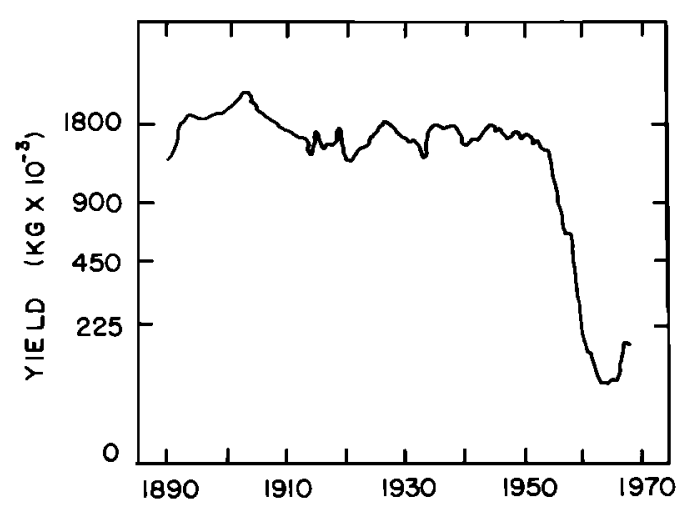

FIGURE 1.-Lake trout yield from Lake Superior, 1879 1970 (Lawrie and Rahrer 1973).

larly well suited for the Great Lakes fisheries because of the large quantity of catch and effort data that are available.

\section{YIELD DATA}

Total lake trout yield from Lake Superior from 1879 to 1970 is shown in Figure 1. Yield data for the developmental stage of the fishery, which occurred before 1879, are not available. Yield was remarkably steady from 1879 to 1953 ; then a rapid decrease in yield began.

Statistical districts were established for the Great Lakes in the early 1920's and annual yield and effort for important commercial fisheries are reported by district (Hile

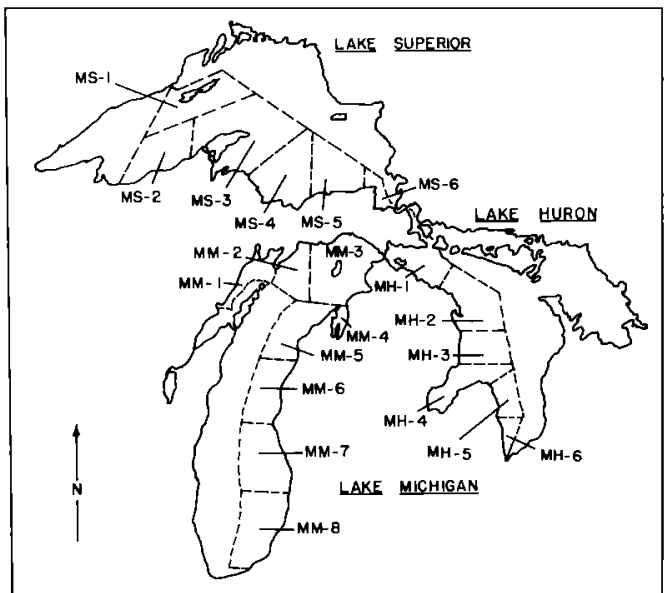

FIGURE 2.-Fishery statistical districts for the State of Michigan in the upper Great Lakes.

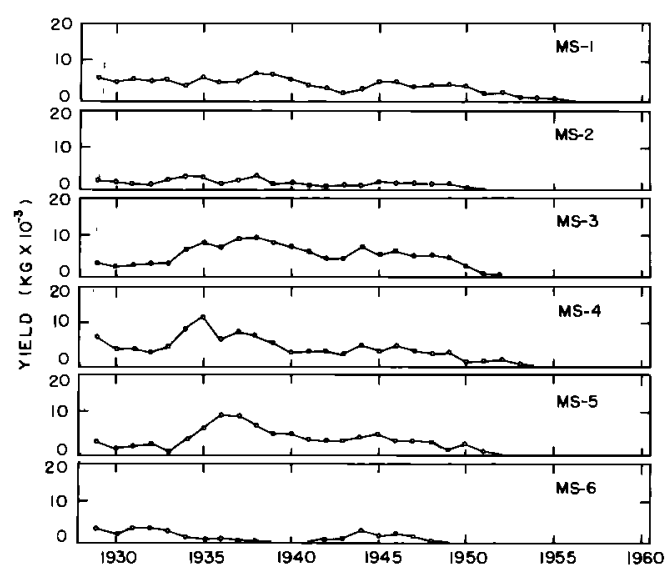

F1GURE 3.-Lake trout yield with set hooks from State of Michigan districts, $1929-1960$.

1962); routine collection of yield and effort data for all State of Michigan districts began in 1929. Fishery districts for Michigan waters of the upper Great Lakes are shown in Figure 2.

The main gears used for lake trout in Lake Superior were 11.4-cm mesh gill nets and set hooks. These gears caught more than $95 \%$ of the lake trout. The gill-net and set-hook yields from Michigan's districts of Lake Superior from 1929 to 1960 are shown in Figures 3 and 4 . Yields with set hooks became zero in all districts during the 1950's; yields with gill nets became small but were always greater than zero.

Fluctuations in lake trout yield have been

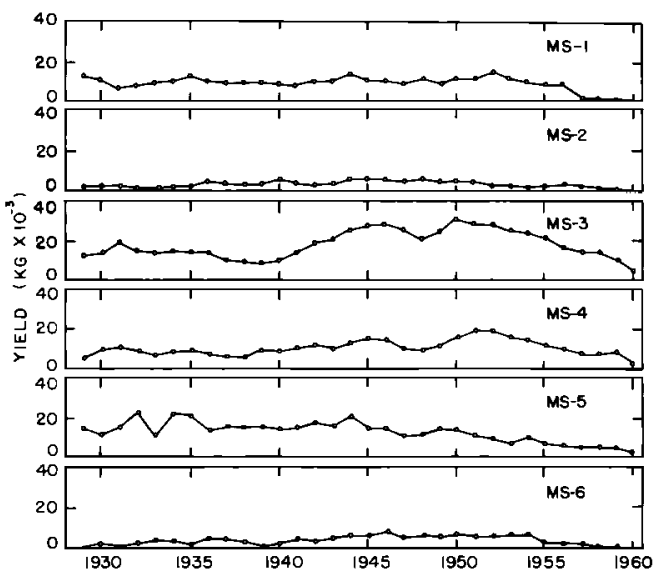

FIGURE 4.-Lake trout yield with 11.4-cm gill nets from State of Michigan districts, 1929-1960. 
small compared to fluctuations in lake whitefish (Coregonus clupeaformis) yields (Jensen 1976; Jensen and Buettner 1976). Lake trout recruitment apparently was fairly stable whereas lake whitefish recruitment varied considerably from year to year. Smith (1968) has compared the lake trout fishery in the Great Lakes with the lake trout fishery in Great Slave Lake where recruitment also was not strongly cyclic and annual fluctuations in year-class strength were not large.

Hile et al. (1951) reported cyclic fluctuations in lake trout yield with maximums occurring near 1935 and 1945. Figures 3 and 4 indicate that such maximums occur in both the set-hook and gill-net data of most districts but they are not large or distinct.

Some consistent patterns in yield appear over all Lake Superior districts. Yields with set hooks were highest from 1930 to 1940 in all districts and yields with gill nets were highest from 1940 to 1955 in all districts except district MS-5. A dip in gill-net yields occurred from 1946 to 1948 in districts MS2, MS-3, and MS-4. Yields were largest in districts MS-3 and MS-4 in the central part of the lake and much less in the western and eastern districts of the lake. In districts MS1, MS-2, MS-4, and MS-6 total yield was stable from 1929 to 1955 with only small fluctuations. In district MS-5 gill-net yield, set-hook yield, and total yield all declined slowly from 1929 onwards. In district MS-3 total yield increased slightly from 1929 to 1950 and then began a gradual decline. Yield from district MS-3 was large and when the data for all districts are combined a gradual increase in yield appears to have occurred from 1929 to about 1945 as was reported by Hile et al. (1951). The differences in the catch histories among the different districts might be important; however, they probably reflect behavior of fisherman and marketing conditions as well as the nature of the populations.

\section{SURPLUS PRODUCTION MODEL}

The logistic surplus production model was developed by Hjort et al. (1933), Graham (1935), and Schaefer (1954). The logistic surplus production model assumes that change in yield with respect to time is pro- portional to the product of effort and biomass and that change in biomass is a quadratic function of population size, i.e.,

$$
\begin{aligned}
& \frac{d Y}{d t}=q E B \text { and } \\
& \frac{d B}{d t}=k B-\left(k / B_{\infty}\right) B^{2}-q E B,
\end{aligned}
$$

where $Y=$ yield in $\mathrm{kg}$;

$t=$ time in years;

$q=$ catchability coefficient;

$E=$ fishing effort;

$B=$ population biomass in $\mathrm{kg}$;

$k=$ population growth parameter;

$B_{\infty}=$ environmental carrying capacity in $\mathrm{kg}$.

Surplus production models are applied to determine the maximum sustainable yield, MSY, and the level of fishing effort that will produce the MSY. The biomass at which the MSY occurs is $B_{\infty} / 2$ and the MSY is $k B_{\infty} / 4$. The instantaneous fishing mortality coefficient at the MSY is $k / 2$, and the fishing effort that will produce the MSY is $k / 2 q$. The logistic surplus production model also can be applied to predict the annual yield that will be obtained from a given level of effort.

Application of a surplus production model requires several assumptions. Jensen (1976) briefly discusses these assumptions as they relate to the Great Lakes whitefish fishery. Pella and Tomlinson (1969) discuss the assumptions in more detail. The assumptions are (1) the fishery operates deterministically; (2) the population in each statistical district is a unit stock; (3) biomass is proportional to yield per unit of effort; (4) there are no time lags; and (5) the shape of the equilibrium stock production curve is a parabola. Furthermore, the model ignores age structure and fluctuations in year-class size.

Some of these assumptions are realistic. Deterministic models adequately describe the mean behavior of a population when the population is large. A time series analysis detected no time lags in the lake trout fishery. It cannot be determined if the stock production curve is a parabola using available data but a more complex curve is not justified. It also cannot be determined if yield per unit of effort is proportional to bio- 


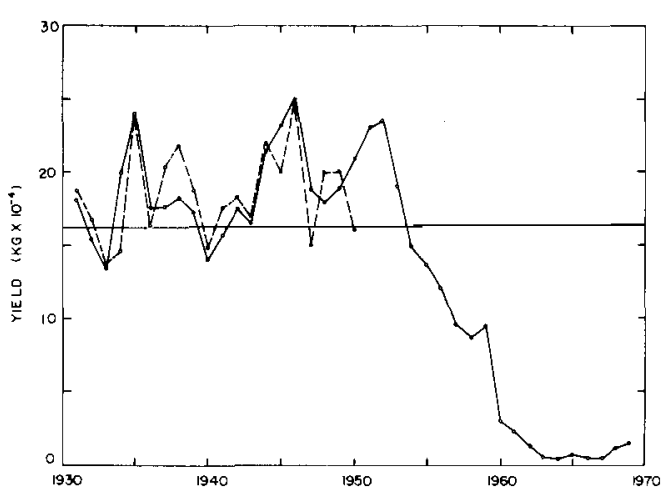

Figure 5.-Observed lake trout yields (solid line) and yields predicted by the surplus production model (dashed line) for district MS4. The solid horizontal line is the MSY.

mass but this assumption has been widely applied to the Great Lakes fisheries as well as to many other fisheries and appears reasonable.

Some assumptions may not be realistic. The lake trout caught in each statistical district probably do not come from the same unit stock. Rahrer (1968) showed that although lake trout adults dispersed from the Gull Island shoal spawning site after spawning, most of them returned to this site for spawning the following year. It is probable that during most of the year there is some mixing of different spawning stocks in the statistical districts. Paulik and Greenough (1966) have suggested an operational definition of a stock useful for the Great Lakes, which states that a stock is simply a group of fish that would be treated as a homogeneous unit in a management program. This approach is necessary for now, but identification of the different stocks is important for sound management of the fisheries.

In certain situations the age structure can be important. Application of the surplus production model for calculation of the MSY assumes that the population achieves an equilibrium where $d B / d t=0$. For a population with several age-groups and variable recruitment, equilibrium might never occur. More or less regular cycles in yield and biomass might occur as large year classes periodically pass through the fishery. In such situations the concept of the MSY may need to be stated in statistical terms. Given these

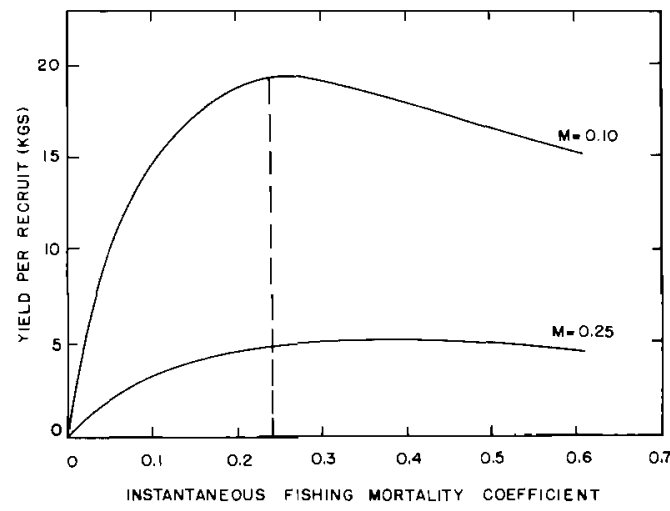

FIGURE 6.-Relation between yield per recruit and fishing mortality coefficient (solid line) obtained by Sakagawa and Pycha (1971) and the optimum level of the fushing mortality coefficient (dashed line) predicted by the surplus production model.

several assumptions together with the lack of data on the developmental phase of the fishery, a reasonable approach is to apply the model and determine how well it fits the data. Predictions of the model then can be compared with new data and with predictions of other models whenever possible.

\section{ASSESSMENT OF THE LAKE SUPERIOR FISHERY}

To assess the effects of fishing the surplus production model was applied to the data from district MS-4. District MS-4, located in south central Lake Superior, was a large producer of lake trout and is fairly typical of the State of Michigan districts of Lake Superior (Figs. 3 and 4). The major gear used for lake trout from 1929 to 1950 was the 11.4-cm mesh cotton gill net. Hile (1962) defined one lift of $305 \mathrm{~m}$ (1,000 linear feet) of gill net as one unit of effort. Set hooks were also important gear in past years and pound nets were used in some districts. To apply the surplus production model all yield and effort data were converted to $11.4-\mathrm{cm}$ mesh gill nets using the procedure recommended by Gulland (1969) in which the catch per unit of effort is calculated for the standard gear (gill nets) and then the effort necessary to make the entire catch using the standard gear is calculated. Change in gear efficiency is not a serious problem because the analyses were done using data from 1929 


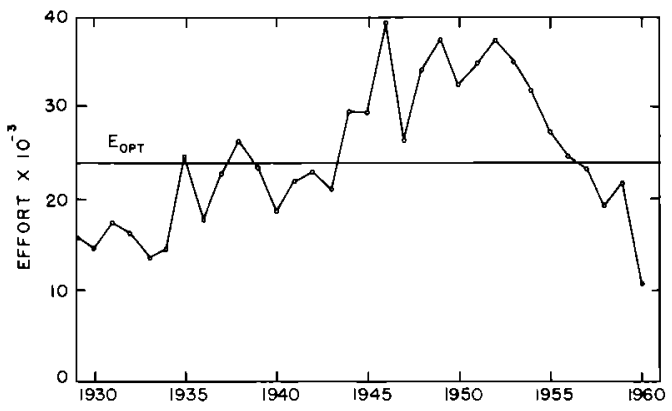

FIGURE 7.-Fishing effort for district MS-4; one unit of effort is 91.4 linear meters of $11.4-\mathrm{cm}$ mesh gill net. The horizontal line is the fishing effort which would produce the MSY.

to 1950 . Nylon and monofilament nets were used after 1950.

The parameters were estimated by nonlinear least squares (Pella and Tomlinson 1969) using data from 1929 to 1950 . The estimates of the parameters are $k=0.48$, $B_{\infty}=1,411,774$, and $q=0.10 \times 10^{-4}$; these parameter values provide a good fit of observed yields to calculated yields (Fig. 5). Applying the estimates of the model parameters gives a MSY of $169,412 \mathrm{~kg}$ for district MS-4; the fishing mortality coefficient that will produce the MSY is $F=0.24$ and the fishing effort that will produce the MSY is $E=24,000$ units.

Sakagawa and Pycha (1971) applied Ricker's (1975) dynamic pool model to the lake trout fishery of south central Lake Superior prior to 1950 and their estimate of the level of fishing that would produce the MSY is close to the value obtained using the surplus production model. The relation Sakagawa and Pycha (1971) found between yield per recruitment and the instantaneous fishing mortality coefficient is shown in Figure 6; they were unable to determine precisely the natural mortality coefficient, but they determined that it was between 0.10 and 0.25 . The fishing mortality coefficient calculated from the surplus production model that would produce the maximum yield per recruitment for district MS-4 is plotted as the dashed line in Figure 6. Two fishery models based on entirely different types of data and approaches give nearly the same value for the level of fishing mortality that would have produced the MSY.

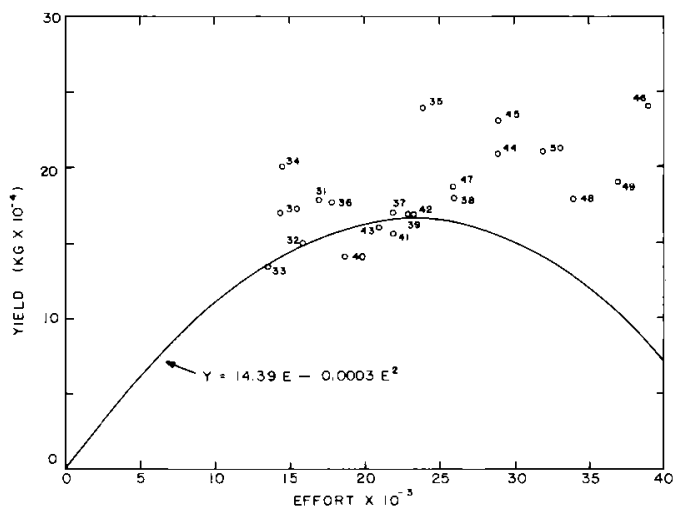

FIGURE 8.-Equilibrium stock production curve for district MSA (parabola) and the observed yields for $1930-1950$.

The fitted surplus production model provides a basis for quantative analysis of the large volume of catch and effort data available for lake trout. Prior to 1944 yield fluctuated about the MSY (Fig. 5) but on the average yield was somewhat larger than the MSY. Except for 1934 and 1935, when large yields were obtained, the observed yield and effort data from 1929 to 1944 are fairly close to the estimated equilibrium stock production curve. During the period 1929 to 1944 the fishery appears to have operated near the MSY and while the average yield was somewhat greater than the MSY (Fig. 5) the level of fishing effort (Fig. 7) was below the level that would have produced the MSY.

Fishing effort increased from 1929 to 1938 and from 1943 into the early 1950's. Higher effort from 1929 to 1938 was associated with a peak in biomass. The higher effort after 1943 resulted from fishermen moving to Lake Superior as stocks declined in the lower Great Lakes. The increasing effort after 1943 produced slightly higher yields as the stock was fished up and the observed yield and effort data from 1945 to 1950 are above and to the right of the equilibrium stock production curve (Fig. 8). If fishing effort had remained at the high levels of 1945 to 1950 , and if sea lamprey had not invaded the lake, yield still would have decreased by about $30 \%$ as the stock was fished up and the equilibrium surplus production level was approached.

Hile et al. (1951) proposed an index of 


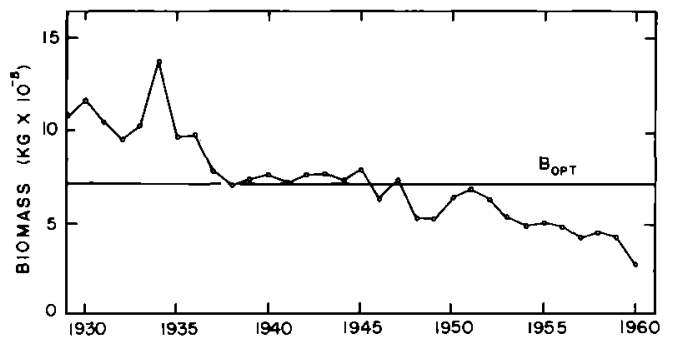

FIGURE 9.-Estimated stock biomass in district MSA. The horizontal line is the biomass level at which the MSY would occur.

abundance in which the observed catch per unit of effort was divided by the average catch per unit of effort for the 15 -yr period 1929 to 1943. This index has been widely applied for assessment of the Great Lakes fisheries. The fitted surplus production model enables direct estimation of stock biomass using the equation $B=C P E / q$. Although Hile's index of abundance and population biomass are calculated using somewhat different methods the results are proportional and the patterns are identical. The biomass estimates are more useful than the abundance index values because they enable determination of the level of exploitation as well as the pattern of stock abundance. From 1929 to 1945, except for 1938, the biomass of the stock was above the level that would have produced the MSY and in this sense the fishery was not overexploited until after 1945 (Fig. 9). Stock size decreased slowly from 1946 to 1960 .

Fluctuations in the biomass estimates are similar to the fluctuations in the yield and effort data but the fluctuations in biomass are considerably smaller. A sizeable maximum in biomass occurred in 1935 when yield and effort also peaked. Yield reached sizable maximums in 1947 and 1953; biomass also peaked at these years but the maximums were small. The biomass maximum in 1947 interrupts an otherwise steep decline in biomass that occurred between 1945 and 1949. Lake trout biomass increased from 1949 to 1951 in spite of heavy fishing pressure. The biomass maximums must have resulted from strong year classes and it appears that considerable excess fish- ing capacity existed; when a large year class was recruited fishing effort increased quickly and produced large yields.

The surplus production model enables direct assessment of the effects of fishing. Assessment of the effects of sea lamprey predation is more difficult. The lamprey was first reported in Lake Huron in 1932 and in Lake Michigan in 1936. Approximately 9 and $7 \mathrm{yr}$ later, in 1941 in Lake Huron and in 1943 in Lake Michigan, a precipitous collapse of the lake trout fisheries began. By 1945 yields in Lake Huron had been reduced by about $75 \%$ and yields in Lake Michigan had been reduced by about $60 \%$.

Sea lamprey were first reported in Lake Superior in 1946. If sea lamprey caused the collapse of the lake trout stocks in Lake Superior, the collapse should have occurred between 1951 and 1956. Yield remained high from Lake Superior until 1952 and then a steep decline began as would have resulted from sea lamprey predation. However, the biomass estimates indicate the decline in biomass below $B_{\infty} / 2$ began in about 1945 . This resulted from overexploitation. There is no change in the biomass estimates after 1945 that corresponds with the sharp changes that occurred in yield and effort in 1953. The time at which sea lamprey predation became important cannot be detected by examination of the biomass estimates; however, when fishing effort and yield began to decrease sharply in 1953 biomass did not increase which indicates sea lamprey predation must have become important soon after 1953. The number of sea lamprey caught at mechanical and electrical barriers began to increase rapidly in 1954 and their numbers reached a maximum in about 1958 (Smith 1968).

Changes in yield and effort (Figs. 5 and 7) are far more dramatic than the changes in biomass (Fig. 9). Biomass appears to have decreased slowly over a long period of time as a result of first overfishing and than sea lamprey predation. Yield and effort both decreased quickly after 1953. Apparently when biomass reached low levels fishing became unprofitable and fishing ended abruptly, resulting in a sharp decrease in yield and effort. 


\section{ACKNOWLEDGMENTS}

J. Van Oosten and R. Hile initiated collection of the data upon which this study is based. The data were made available to me by H. Buettner. S. H. Smith and M. Patriarche read the original manuscript and made many helpful suggestions. R. L. Pycha and T. M. Stauffer also made several helpful suggestions. This study was supported by the Michigan Sea Grant Program which is sponsored by NOAA Office of Sea Grant, Department of Commerce, under grant 04-6-158-44097.

\section{REFERENCES}

Baldwin, N. S., ANd R. W. SaAlfeld. 1962. Commercial fish production in the Great Lakes: 18671960. Great Lakes Fish. Comm. Tech. Rep. 3. $166 \mathrm{pp}$.

Graham, M. 1935. Modern theory of exploiting a fishery, and applications to North Sea trawling. J. Cons., Cons. Int. Explor. Mer 10:264-174.

Gulland, J. A. 1969 . Manual of methods for fish stock assessment part 1. Fish population analysis. FAO Man. Fish. Sci. 4. 154 pp.

HıLe, R. 1962. Collection and analysis of commercial fishing statistics in the Great Lakes. Great Lakes Fish. Comm. Tech. Rep. 5. 31 pp. , P. H. Eschmeyer, and G. F. Lunger. 1951. Status of the lake trout fishery in Lake Superior. Trans. Am. Fish. Soc. 80:278-312.

Hjort, J., G. Jahn, and P. Ottestad. 1933. The optimum catch. Hvalradets Skr. 7:92-127.

Jensen, A. L. 1976. Assessment of the United States lake whitefish (Coregonus clupeaformis) fisheries of Lake Superior, Lake Michigan, and Lake Huron. J. Fish. Res. Board Can. 33:747-759.

, AND H. J. BuetTner. 1976. Lake trout, whitefish, chubs, and lake herring yield and effort data for State of Michigan waters of the upper Great Lakes: 1929-1973. Mich. Sea Grant Tech. Rep. $52.85 \mathrm{pp}$.

Lawrie, A. H., AND J. F. Rahrer. 1973. Lake Superior, a case history of the lake and its fisheries. Great Lakes Fish. Comm. Tech. Rep. 19. 69 pp.

Paulik, G. J., and J. W. Greenough, Jr. 1966. Management analysis for a salmon resource system. Pages 215-252 in K. E. F. Watt, ed. Systems analysis in ecology. Academic Press, New York.

Pella, J. J., AND P. K. Tomlinson. 1969. A generalized stock production model. Inter-Am. Trop. Tuna Comm. Bull. 13:421-496.

Pycha, R. L., AND G. R. King. 1975. Changes in the lake trout population of southern Lake Superior in relation to the fishery, the sea lamprey, and stockings 1950-70. Great Lakes Fish. Comm. Tech. Rep. 28. 34 pp.

RAHRER, J. F. 1968. Movements of adult lake trout in Lake Superior. Trans. Am. Fish. Soc. 97:481-484.

RICKER, W. E. 1975. Computation and interpretation of biological statistics of fish populations. Fish. Res. Board Can. Bull. 191. 382 pp.

Sakagawa, G. T., and R. L. Pycha. 1971. Population biology of lake trout (Salvelinus namaycush) of Lake Superior before 1950. J. Fish. Res. Board Can. 28:65-71.

SCHAEFER, M. B. 1954. Some aspects of the dynamics of populations important to the management of the commercial marine fisheries. Inter-Am. Trop. Tuna Comm. Bull. 1:27-56.

SмiтH, S. H. 1968. Species succession and fishery exploitation in the Great Lakes. J. Fish. Res. Board Can. 25:667-693. 